\title{
Influence of ice-sheet geometry and supraglacial lakes on seasonal ice-flow variability
}

\author{
I. Joughin ${ }^{1}$, S. B. Das ${ }^{2}$, G. E. Flowers ${ }^{3}$, M. D. Behn ${ }^{2}$, R. B. Alley ${ }^{4}$, M. A. King ${ }^{5,6}$, B. E. Smith ${ }^{1}$, J. L. Bamber ${ }^{7}$, \\ M. R. van den Broeke ${ }^{8}$, and J. H. van Angelen ${ }^{8}$ \\ ${ }^{1}$ Polar Science Center, Applied Physics Lab, University of Washington, 1013 NE 40th St., Seattle, WA 98105-6698, USA \\ ${ }^{2}$ Department of Geology and Geophysics, Woods Hole Oceanographic Institute, Woods Hole, MA 02543, USA \\ ${ }^{3}$ Department of Earth Sciences, Simon Fraser University, 8888 University Drive, Burnaby, British Columbia, V5A 1S6, \\ Canada \\ ${ }^{4}$ Department of Geosciences, and Earth and Environmental Systems Institute, Pennsylvania State University, University Park, \\ PA 16802, USA \\ ${ }^{5}$ School of Geography and Environmental Studies, University of Tasmania, Private Bag 76, Hobart, Tasmania, 7001, Australia \\ ${ }^{6}$ School of Civil Engineering and Geoscience, Newcastle University, Newcastle upon Tyne, NE1 7RU, UK \\ ${ }^{7}$ Bristol Glaciology Centre, School of Geographical Sciences, University of Bristol, University Road, Bristol, BS8 1SS, UK \\ ${ }^{8}$ Institute for Marine and Atmospheric Research, Utrecht University, 3584 CC Utrecht, the Netherlands
}

Correspondence to: I. Joughin (ian@apl.washington.edu)

Received: 22 February 2013 - Published in The Cryosphere Discuss.: 13 March 2013

Revised: 13 June 2013 - Accepted: 17 June 2013 - Published: 26 July 2013

\begin{abstract}
Supraglacial lakes play an important role in establishing hydrological connections that allow lubricating seasonal meltwater to reach the base of the Greenland Ice Sheet. Here we use new surface velocity observations to examine the influence of supraglacial lake drainages and surface melt rate on ice flow. We find large, spatially extensive speedups concurrent with times of lake drainage, showing that lakes play a key role in modulating regional ice flow. While surface meltwater is supplied to the bed via a geographically sparse network of moulins, the observed ice-flow enhancement suggests that this meltwater spreads widely over the ice-sheet bed. We also find that the complex spatial pattern of speedup is strongly determined by the combined influence of bed and surface topography on subglacial water flow. Thus, modeling of ice-sheet basal hydrology likely will require knowledge of bed topography resolved at scales (sub-kilometer) far finer than existing data (several $\mathrm{km}$ ).
\end{abstract}

\section{Introduction}

Summer surface meltwater descends through hundreds of meters of glacial ice (Das et al., 2008; Doyle et al., 2013) to lubricate the base of the Greenland Ice Sheet, seasonally enhancing ice flow (Zwally et al., 2002). While this enhancement does not account for recent large increases in mean-annual ice-flow speed (Joughin et al., 2008), it may become more important in controlling Greenland's contribution to sea level in the coming decades to centuries as marine-terminating outlet glaciers retreat from their deep troughs (Parizek and Alley, 2004). Several recent studies have shown that this sensitivity to surface melt is complex (e.g., Sundal et al., 2011; Bartholomew et al., 2011b; van de Wal et al., 2008), depending greatly on the temporal variability of meltwater delivery to the bed (Schoof, 2010). To examine further the seasonal influence of surface meltwater production on ice-sheet flow, we selected a region along Greenland's west coast where there are numerous supraglacial lakes (Figs. 1 and 2). This area predominantly feeds three relatively slow-moving $\left(<200 \mathrm{~m} \mathrm{yr}^{-1}\right)$ outlet glaciers (Sarqardliup sermia, Alángordliup sermia and Nordenskiöld Gletscher) just south of the rapidly flowing 


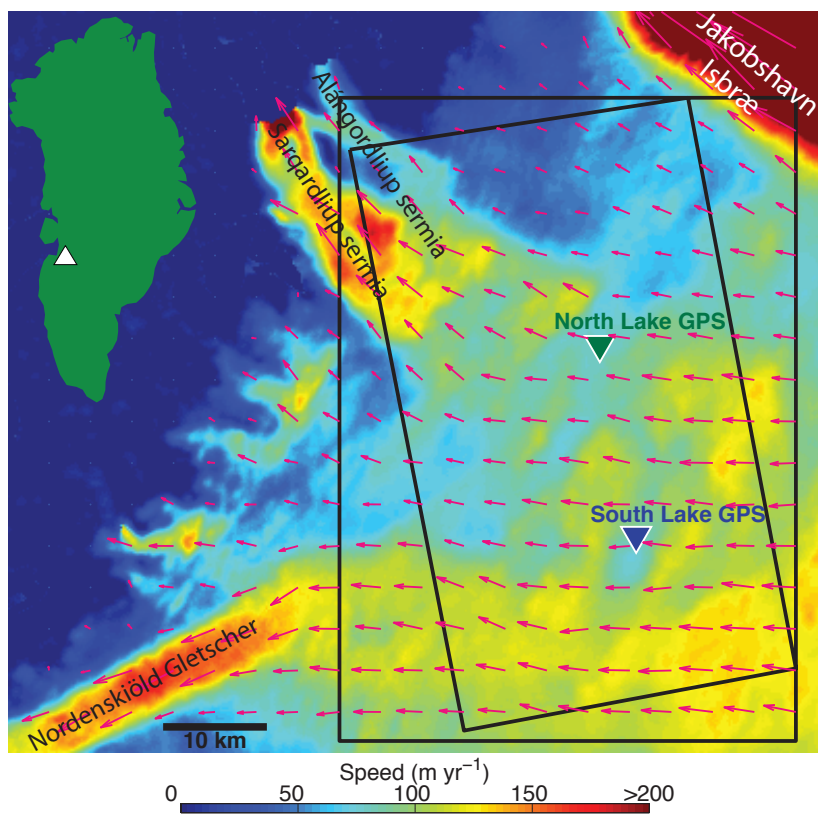

Fig. 1. Map of average flow velocity (arrows and color) from RADARSAT data collected in the winters of 2007-2009 with inset map showing location. Black rectangles show the areas displayed in Figs. 2-4, and triangles show the location of GPS stations used as control points.

Jakobshavn Isbræ (Fig. 1). At two sites in this region (north and south lakes, Fig. 1), we have collected GPS data throughout the year starting in 2006 (Joughin et al., 2008). To provide better spatial coverage for 2009 and 2010, we requested repeat acquisition of TerraSAR-X synthetic aperture radar data from the German Space Agency (DLR) for velocity mapping. We have used these data to produce time series of velocity variation over an approximately $33 \mathrm{~km}$-by- $57 \mathrm{~km}$ area throughout the 2009 and 2010 melt seasons as described below.

\section{Results}

We began by mapping our study area's surface hydrological features (Fig. 2a), using high-resolution $(\sim 0.6 \mathrm{~m})$ WorldView optical imagery (2009-2011). Streams were digitized by manually tracing them as far upstream as they were visible in the imagery. With this imagery, it is possible to identify distinct, quasi-linear features such as streams and crevasses with widths well below the image resolution (i.e., a few $10 \mathrm{~s}$ of $\mathrm{cm}$ ). Instead of digitizing every stream, we digitized a subset ( $<\sim 20 \%$ ) of streams with a density sufficient to reveal qualitatively the spatial extents of the catchments and corresponding stream networks feeding each lake. Because they were easily identifiable, we digitized most moulins in the lake-dominated regions. At lower elevations $(<800 \mathrm{~m})$ there were other surface features (e.g., crevasses) that made moulin identification more difficult. As a result, we could not identify a substantial fraction of the moulins at lower elevations. We also may have misidentified some features as being active moulins that instead were extinct moulins from past summers.

Lake basin outlines were identified automatically using six summers (2001-2006) of daily MODIS data. These outlines represent the maximum areal extent of the lakes over this period. Thus, the maximum areal extent of individual lakes in 2009 and 2010 may have been substantially less than indicated by their corresponding outlines. Timing of lake drainage with 11-day resolution was determined from the TerraSAR-X images. We classified lakes as either "slowly draining", if drainage starts in one 11-day interval but continues into another interval, or "rapidly draining", if drainage starts and is completed within a single 11-day interval. Past observations suggest that complete drainage occurs within several hours for our rapidly draining lakes (Das et al., 2008; Doyle et al., 2013; Selmes et al., 2011 ), but we cannot exclude the possibility that some may have drained over several days ( $<11$ days).

The mapped drainage features are shown plotted over a TerraSAR-X image (Fig. 2a) and a map of bedrock topography (Fig. 2b; Bamber et al., 2013). The digitized features indicate that, above $\sim 800 \mathrm{~m}$ elevation, lakes tend to be larger ( $>1 \mathrm{~km}$ diameter) and moulins are more widely spaced (several $\mathrm{km}$ ) compared to those at lower elevation, where lakes tend to be smaller and moulins are more densely spaced (Fig. 2a). Figure 2a also shows regions of high strain rate where crevasses are most likely to form. With the exception of these high-strain-rate areas where meltwater likely drains into crevasses rather than via surface streams, the overall pattern of sparsely distributed moulins fed by extensive stream networks in the lake-dominated region is qualitatively robust and consistent with observations elsewhere in Greenland (Phillips et al., 2011).

We mapped ice velocity with dense spatial coverage by applying speckle-tracking methods (Joughin, 2002) to singlelook complex TerraSAR-X radar images collected through the 2009 and 2010 melt seasons. Except for two instances when missed 2010 acquisitions yielded images separated by 22 days, these data yield velocity estimates averaged over 11-day intervals, providing more regular and frequent sampling than earlier studies (Joughin et al., 2008; Palmer et al., 2011; Sundal et al., 2011). The orbital baselines used to determine velocity were estimated using the DLR science orbits combined with known velocity from at least one point. These control velocities were computed specific to each 11or 22-day period using data from GPS receivers located at the North and South lakes (Fig. 1), which were processed using the GIPSY software with precise point positioning (PPP) (King and Aoki, 2003). Small errors in the TerraSAR-X orbit data may yield nearly linear trends across each map. Comparison with data from overlapping orbits indicates that these errors are small ( $<10 \%$ of nominal winter speed). For 


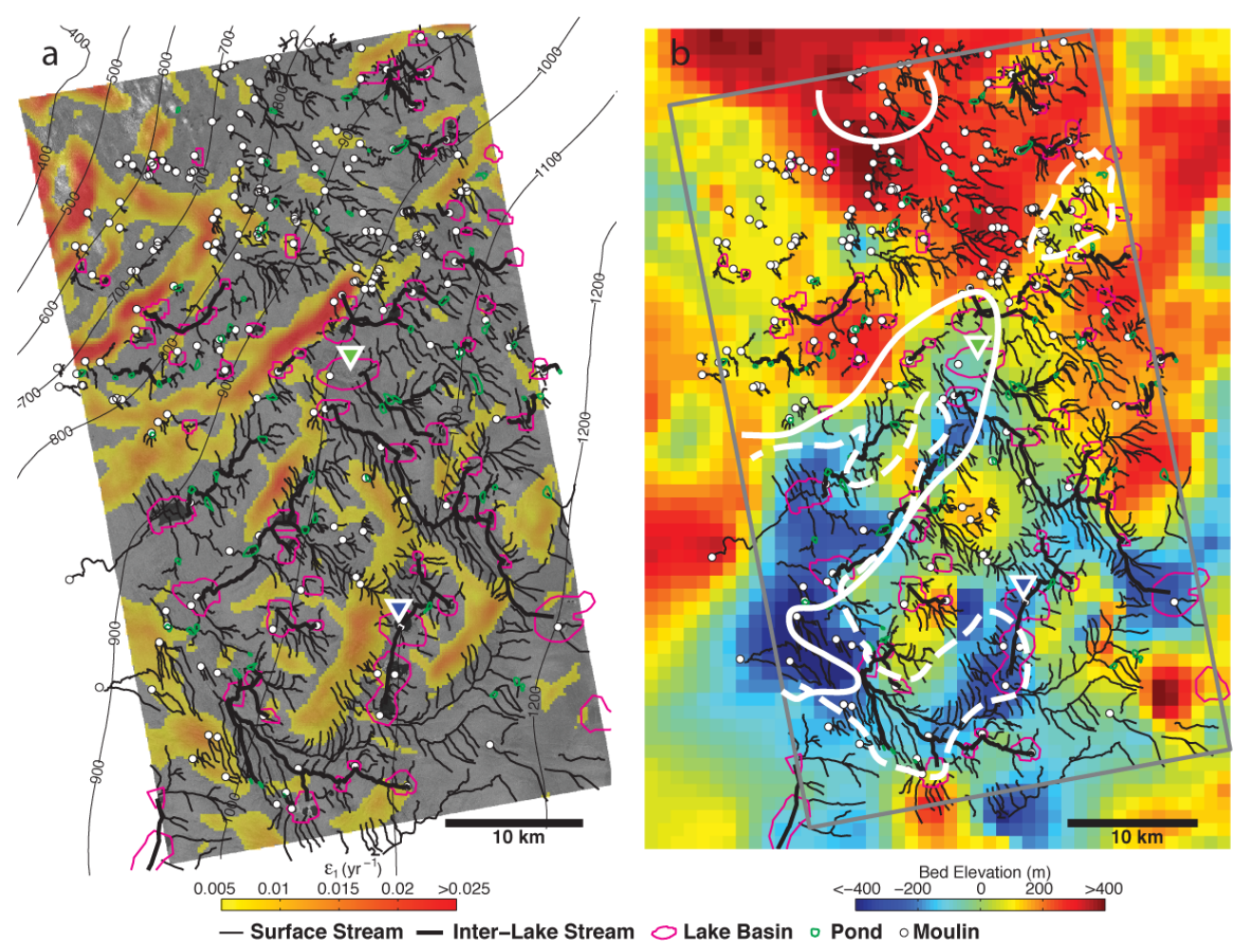

Fig. 2. (a) TerraSAR-X image (copyright DLR 2009) showing study area over-plotted with surface hydrological features. Color indicates principal surface strain rates for magnitudes approximately sufficient to cause crevassing, and contours show surface elevation. Streams were hand-digitized from high-resolution WorldView imagery; only a small fraction of the streams visible in the imagery are shown (see Methods). Triangles show the locations of GPS stations adjacent to North and South lakes. (b) Basal topography (Bamber et al., 2013) is overplotted with surface hydrological features. Although the digital elevation model is posted at $1 \mathrm{~km}$, it was generated from sparse flights separated by many kilometers, so the true resolution is variable and much poorer than $1 \mathrm{~km}$. White lines indicate approximate extent of the areas where speedup exceeded $100 \%$ on 15 July 2009 (dashed) and 10 June 2010 (solid) as indicated by the data shown in Figs. 3 and 4, respectively.

the nominal winter speed, we averaged three estimates collected in April 2009, November 2010, and February 2011. Seasonal speedup during 2009 and 2010 derived from the TerraSAR-X data, expressed as a percentage of the nominal winter speed, is compared to the timing and style (rapid vs. slow) of lake drainage in Figs. 3 and 4, respectively. These figures also show average melt, $m_{\text {avg }}$, for each time period as determined using the Regional Atmospheric Climate MOdel v.2 (RACMO2; van Angelen et al., 2012) daily meltwater runoff estimates.

Lakes that drain rapidly (often within hours; green solid fill and outlines in Figs. 3 and 4) often do so through large hydrofractures along which moulins later develop, supplying water to the bed for the remainder of the melt season (Alley et al., 2005; Das et al., 2008; Krawczynski et al., 2009; van der Veen, 2007; Doyle et al., 2013). Slowly draining (over weeks) lakes (purple solid fill and outlines) tend to fill until they eventually overflow to drain through an outlet stream leading to a moulin. Once a lake begins to overflow, surface drawdown continues as thermal erosion from the viscous dissipation ("friction") in the flowing water deepens outletstream channels, often by several meters in a summer near our field camps in the study area. Thus, while the lake's reservoir of water lasts, slow lake drainages augment the daily melt volume reaching the bed.

Earlier and less frequent (24-day) synthetic aperture radar (SAR) data indicate a spatially uniform early summer speedup in our study region (Joughin et al., 2008), whereas our more frequent TerraSAR-X estimates show considerably greater spatial heterogeneity and resolve more temporal variability. The TerraSAR-X data from 2009 (Fig. 3) show a large regional speedup $(>100 \%)$ in mid-July near the period of peak melt and at a time when most nearby lakes had established connections to the bed. Prior to this regional speedup, there were several isolated speedups as individual lakes drained (e.g., near North Lake during the 11day interval centered on 12 June shown in Fig. 3). In 2010 a large speedup with a similar spatial pattern to 2009 occurred in early to mid-June, concurrent with the period when many lakes began to drain. Speeds dropped sharply in 2009 from $>100 \%$ to $\sim 20 \%$ above winter values after the main speedup event. By contrast, for approximately three weeks after the main speedup in 2010, flow remained moderately enhanced (40-80\%) before dropping to late summer speeds 


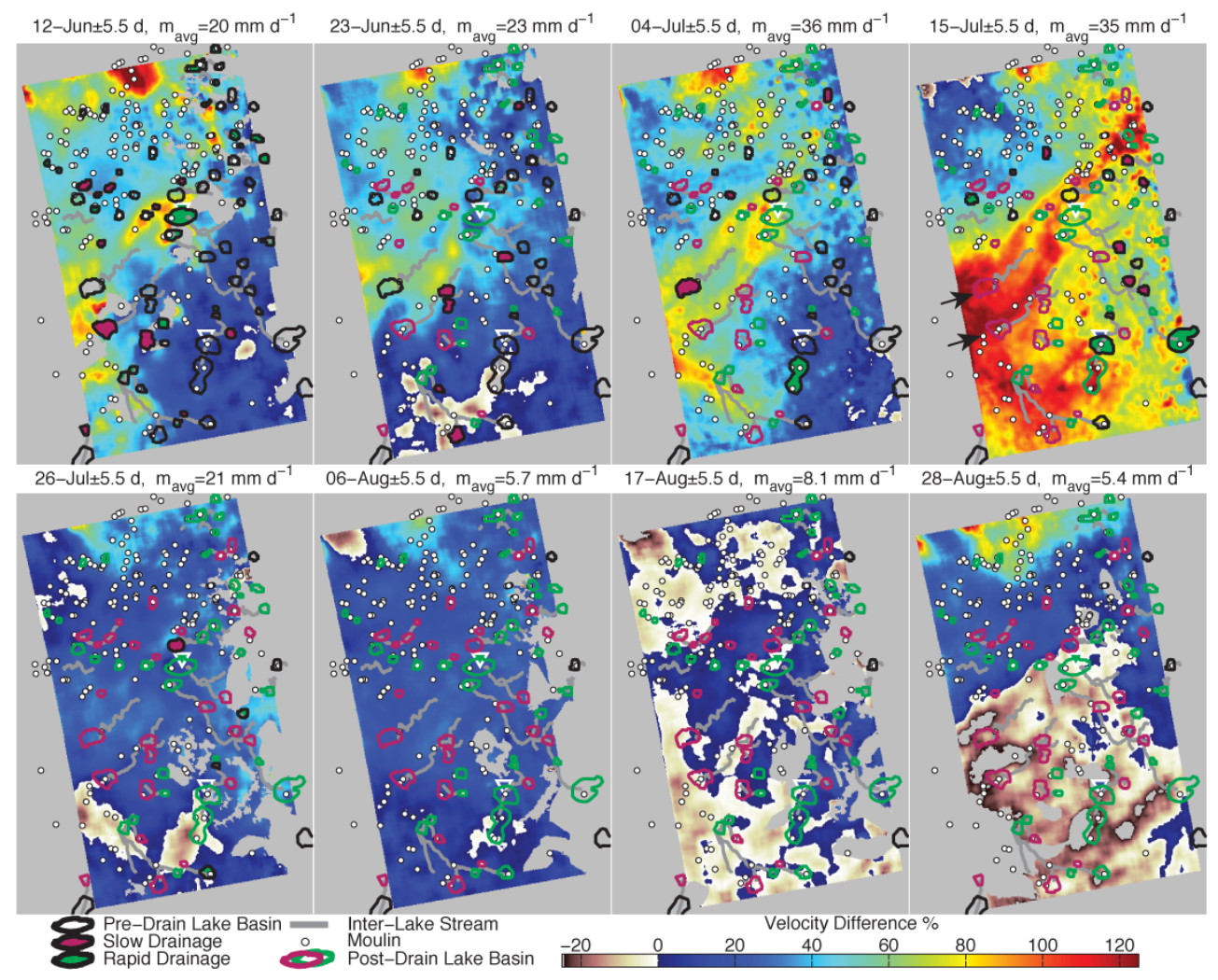

Fig. 3. Increase in summer 2009 flow speed relative to the winter velocity expressed as a percentage of the winter speed with gray to indicate regions of no data. The date for each panel corresponds to the central date for each 11- or 22-day interval over which velocity is determined. Also plotted are the surface features shown in Fig. 1, excluding smaller surface streams, with color coding to indicate the 11-day interval when lake drainage commenced. Prior to drainage, lakes are shown with black outlines. A solid fill indicates the period when a lake drained rapidly (green) or began draining slowly (magenta). For the periods following initial drainage, magenta outlines indicate continuing overflow to a nearby moulin. For fast draining lakes, the green outlines indicate the post-drainage period when water inflowing to the lake basin drains directly to the lake's moulin. Triangles show the location of GPS stations with color as indicated in Fig. 1. Mean daily surface melt estimates, $m_{\text {avg }}$, determined using the RACMO2 (van Angelen et al., 2012) are shown beside the corresponding date for each map. Note maximum of speedup on 15 July is located just downglacier of the major surface streams indicated by black arrows (see high-resolution version in Supplement).

similar to 2009. In both years speeds reach seasonal minima over much of the area around the time when surface melt is in strong decline (Figs. 3h and 4h), consistent with GPS observations at North and South lakes in 2006 that show late summer annual minima (Joughin et al., 2008).

\section{Discussion}

In the lake-dominated region (above $\sim 800 \mathrm{~m}$ elevation), the general pattern is a regional speedup concurrent with the period when lakes drain, followed by a trend of declining speed over the remainder of the summer (Fig. 3 and 4). As earlier results suggest (Das et al., 2008; Alley et al., 2005; van der Veen, 2007; Krawczynski et al., 2009; Doyle et al., 2013), our observations indicate that supraglacial lakes play an important role in the seasonal ice dynamics by providing reservoirs of water that facilitate hydrofracture, and conse- quently influence the timing of when surface meltwater first reaches much of the bed. As in other areas at similar elevations (Sundal et al., 2009), the new TerraSAR-X data indicate that similarly timed lake drainages regionally release a large volume of water to the bed over periods of $\sim 10$ to 20 days, often early in the melt season when the basal drainage system should be relatively inefficient (Bartholomew et al., 2011b, 2010). Thus, much of the excess seasonal motion in our study area occurs during the periods when several lakes begin draining (Figs. 3 and 4).

Modeling based on theory developed for mountain glaciers suggests that lubrication from a widely distributed, highpressure basal-water system facilitates fast ice flow (Iken, 1981). In such a system, the viscous dissipation of water flow melts basal ice, enlarging preferred flow paths (Röthlisberger, 1972). Under a sufficiently large, steady water supply, this melting causes the preferred flow paths to develop into a relatively efficient network of a few large 


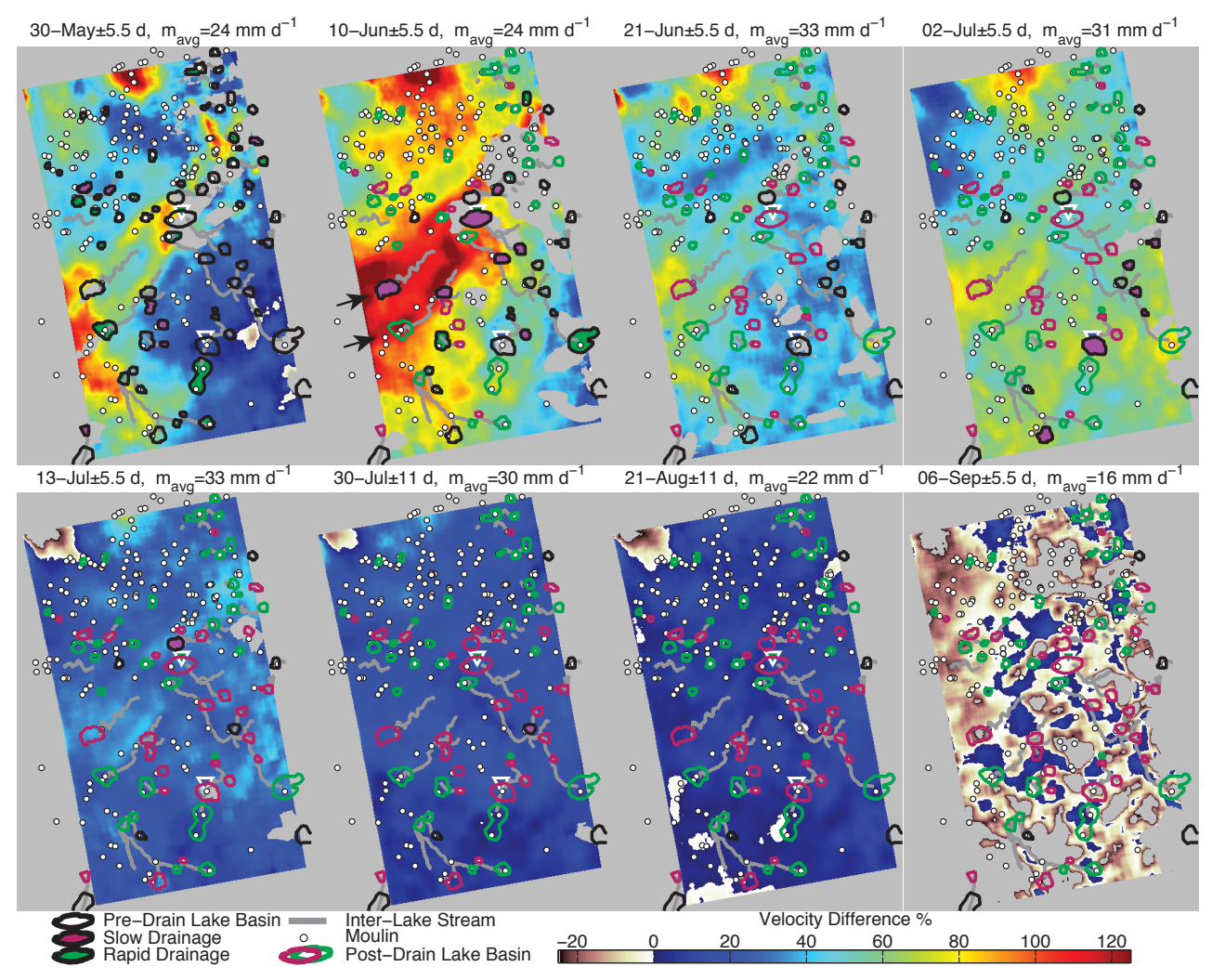

Fig. 4. Difference between summer and winter velocity for 2010. Also plotted are the surface features shown in Fig. 2 with the same color coding as in Fig. 3. Mean daily melt estimates, $m_{\text {avg }}$, determined using RACMO2 (van Angelen et al., 2012) are shown beside the corresponding date for each map. Note maximum of speedup on 10 June is located just downglacier of two major surface streams indicated by black arrows (see high-resolution version in Supplement).

channels (Schoof, 2010). In this case steady-state basal water pressure decreases with increasing discharge, rapidly draining water from the adjacent glacier bed. By contrast, the low water fluxes characteristic of winter allow ice flow to "pinch off" developing subglacial channels, thus maintaining a distributed system (Walder, 1982). If water input transiently increases more rapidly than channels can grow, the excess water is added to the distributed, high-pressure system to produce peak summertime "lubrication" exceeding winter levels (Schoof, 2010).

The relationship between surface melt production and ice-flow speed visible in Figs. 3 and 4 (see melt values at the top of each panel) indicates behavior broadly consistent with the conceptual model described above, which also has been demonstrated with several other observations (e.g., Bartholomew et al., 2010, 2011b; Hoffman et al., 2011; Sole et al., 2011). The largest speedups occur early in the summer before an efficient drainage network has likely developed and when water from lakes augments the daily production of meltwater reaching the bed. Enlargement of subglacial channels by this abundant meltwater input likely increases basal drainage efficiency, and thus decreases the sensitivity of ice velocity to meltwater input starting in approxi- mately mid-July. In 2009, the timing of this decline in sensitivity is roughly consistent with subglacial discharge data for a catchment roughly $175 \mathrm{~km}$ to the south of our site, indicating that the transition to an efficient network was complete by about 16 July (Bartholomew et al., 2011a). In our data, an example of the reduced sensitivity following the development of an efficient drainage is the relatively modest speedup in mid-July 2010 (13 July in Fig. 4) despite comparatively large daily melt rates $\left(m_{\mathrm{avg}}=33 \mathrm{~mm} \mathrm{~d}^{-1}\right)$ at a time when most moulins are actively draining. The timescales over which regional ice speedup evolves in our data are consistent with the development of an efficient drainage system requiring weeks of abundant meltwater supply (Bartholomew et al., 2011a; Schoof, 2010). This timing is also consistent with recent direct observations (hydrochemical and physical) of a seasonal transition from distributed to channelized drainage under land-terminating glaciers in Greenland (Bhatia et al., 2011; Cowton et al., 2012).

Previous modeling indicated that a branching channel network can theoretically develop from a distributed subglacial drainage system fed with uniform water input (Schoof, 2010). Our observations (Fig. 2a) suggest a different picture of water delivery in areas where an extensive supraglacial 
stream network collects water over broad areas and funnels it to the bed through sparsely distributed (e.g., kilometers apart) moulins. At times of rising water input, these point sources likely distribute water widely across the bed, as suggested by the broad pattern of speedup (Figs. 3 and 4), regionally modulating basal water pressure and lubrication. Such spreading is consistent with the previously observed surface uplift in response to water rapidly ( $\sim 90 \mathrm{~min})$ draining from a large lake in our study area (North Lake in Fig. 1) in 2006. The large surface uplift $(>1 \mathrm{~m})$ distant $(\sim 2 \mathrm{~km})$ from the injection source indicates a thick sheet of water spreading rapidly (minutes to hours) away from the lake center (Das et al., 2008; Tsai and Rice, 2010), temporarily lubricating the bed until it is conveyed away from the source by an existing or developing drainage system (Flowers et al., 2004; Pimentel and Flowers, 2011). Similar behavior has been observed during other drainage events (Doyle et al., 2013).

At the ice-sheet surface, stretching and thinning as ice flows over bedrock highs (Fig. 2b) produces regions with high tensile strain rates (Fig. 2a) where crevasses form, serving as potential sites for moulin-forming hydrofractures. Over the intervening bedrock depressions, the local surface slopes can oppose the regional gradient to yield closed basins in which supraglacial lakes form. Because ice flow follows the surface gradient averaged over several ice thicknesses, ice flow can oppose the direction of locally reversed surface gradients. By contrast, surface-water flow conforms to the local surface slope. Consequently, regions of reversed surface slope in our study area lead to a "trellis-style" drainage structure whereby streams can flow roughly transverse to the direction of ice flow, parallel to subglacial troughs located between the bedrock highs (Fig. 2b).

Surface and bed topography influence subglacial water flow through the hydraulic potential. When basal water pressure approaches the ice-overburden pressure, the direction of basal water flow is approximately ten times more sensitive to slopes at the ice surface than at the bed (Cuffey and Paterson, 2010). Bed slopes, however, are typically much larger than surface slopes, so both can be important. The bedrock elevation model (Bamber et al., 2013) (several $\mathrm{km}$ scale) of our study area (Fig. 2b) poorly resolves the type of rugged topography (sub-km scale) observed on nearby, and presumably similar, ice-free terrain, making it difficult to estimate the bed elevation's contribution to the hydraulic potential in detail. Surface streams (Fig. 2), however, provide a rough proxy for the direction of basal water flow to the extent that it is controlled by surface slope.

The spatial patterns of regional speedup correspond well with large-scale variations in bed topography. In particular, the areas of peak (> 100\%) speedup in 2009 and 2010 coincide well with the bedrock troughs and the intervening ridges that lead to surface water flow not well aligned with ice flow (Fig. 2b). In such regions, the hydraulic gradients driving water flow at the bed should be far weaker than where streams parallel ice flow, which should yield slower basal water flow and, in turn, reduce the rate at which turbulent flow enlarges conduits through melting. Weaker gradients driving water flow should also make it relatively easier for water to spread laterally away from moulins or locations of lake drainage. Finally, just as lakes form in surface depressions, water may pond in the corresponding depressions in the basal hydraulic potential until water pressure rises sufficiently to breach the hydraulic barrier. Collectively, these factors should impede basal water flow, and therefore enhance ice flow, in regions where bedrock structures are not well aligned with the regional ice flow (Fig. 2b).

Some areas in Figs. 3 and 4 have major streams not well aligned with ice flow that are located just upglacier of the areas of seasonally enhanced ice flow (e.g., as indicated by arrows for 15 July in Fig. 3 and 10 June in Fig. 4). This may be because, at wavelengths of a few ice thicknesses, the ice surface is largely a muted expression of the bed topography, but shifted in phase upstream by a quarter wavelength (Whillans and Johnsen, 1983). Thus, where surface water is routed roughly transverse to ice flow in regions of high-relief bed, the combined influence of surface and bed on the hydraulic potential should displace basal water flow slightly downglacier relative to the corresponding surfacewater flow. By contrast, where bedrock and surface gradients are well aligned or surface slopes dominate, flow enhancement should be more symmetrically distributed about prominent surface streams as has been observed elsewhere (Palmer et al., 2011).

\section{Conclusions}

The TerraSAR-X data reveal a complex spatiotemporal evolution of ice flow throughout the summer melt season, with the timing of lake drainage determining when much of the widespread seasonal speedup occurs. The complex spatial patterns indicate the difficulties inherent in sampling seasonal variability with sparse networks of GPS receivers (e.g., Joughin et al., 2008; van de Wal et al., 2008; Zwally et al., 2002). Because water and ice flow are not always coaligned, even deploying GPS receivers along a flow line may inadequately sample spatial variation (e.g., Bartholomew et al., 2011b). To a large extent, the observed spatial patterns of flow enhancement can be attributed to surface and bed slopes acting in concert to determine the pathways along which basal water flows, leading to regions of limited drainage and enhanced storage. Consequently, modeling of subglacial hydrology likely requires detailed knowledge of the bed topography at scales of a few ice thicknesses or less. At present most of the Greenland Ice Sheet's bed is not well resolved at such scales, nor are there many hydrological models fully developed to take advantage of such data. As a result, including the influence of surface melt on ice-sheet dynamics remains a challenge for projection of the future ice-sheet evolution. 


\section{Supplementary material related to this article is available online at: http://www.the-cryosphere.net/7/ 1185/2013/tc-7-1185-2013-supplement.pdf.}

Acknowledgements. The final manuscript benefited from comments from M. Pelto and two anonymous reviewers. This work was supported jointly by National Science Foundation's Office of Polar Programs (NSF-OPP) and National Aeronautics and Space Administration's (NASA) Cryospheric Sciences Program (and through ARC-0520382, ARC-1023382 and NNX10AI33G to I. Joughin; and ARC-0520077, ARC-1023364 and NNX10AI30G to S. B. Das and M. D. Behn). The Natural Sciences and Engineering Research Council of Canada (NSERC) and the Canada Research Chairs Program (CRC) provided support for G. E. Flowers. Support for R. B. Alley was provided by NSF (ANT-0424589 and ARC0909335). Contributions by M. A. King were supported by NERC and an Australian Research Council Future Fellowship (project number FT110100207). The TerraSAR-X data were provided by the German Space Agency (DLR), and the WorldView data were provided through the Polar Geospatial Center (PGC). We gratefully acknowledge the help with these data provided by Dana Floricioiu (DLR), Paul Morin (PGC), and Claire Porter (PGC).

Edited by: R. Bingham

\section{References}

Alley, R. B., Dupont, T. K., Parizek, B. R., and Anandakrishnan, S.: Access of surface meltwater to beds of sub-freezing glaciers: preliminary insights, Ann. Glaciol., 40, 8-14, 2005.

Bamber, J. L., Griggs, J. A., Hurkmans, R. T. W. L., Dowdeswell, J. A., Gogineni, S. P., Howat, I., Mouginot, J., Paden, J., Palmer, S., Rignot, E., and Steinhage, D.: A new bed elevation dataset for Greenland, The Cryosphere, 7, 499-510, doi:10.5194/tc-7-4992013, 2013.

Bartholomew, I., Nienow, P., Mair, D., Hubbard, A., King, M. A., and Sole, A.: Seasonal evolution of subglacial drainage and acceleration in a Greenland outlet glacier, Nat. Geosci., 3, 408-411, doi:10.1038/Ngeo863, 2010.

Bartholomew, I., Nienow, P., Sole, A., Mair, D., Cowton, T., Palmer, S., and Wadham, J.: Supraglacial forcing of subglacial drainage in the ablation zone of the Greenland ice sheet, Geophys. Res. Lett., 38, L08502, doi:10.1029/2011g1047063, 2011a.

Bartholomew, I. D., Nienow, P., Sole, A., Mair, D., Cowton, T., King, M. A., and Palmer, S.: Seasonal variations in Greenland Ice Sheet motion: Inland extent and behaviour at higher elevations, Earth Planet Sc. Lett., 307, 271-278, doi:10.1016/J.Eps1.2011.04.014, 2011b.

Bhatia, M. P., Das, S. B., Kujawinski, E. B., Henderson, P., Burke, A., and Charette, M. A.: Seasonal evolution of water contributions to discharge from a Greenland outlet glacier: insight from a new isotope-mixing model, J. Glaciol., 57, 929-941, 2011.

Cowton, T., Nienow, P., Bartholomew, I., Sole, A., and Mair, D.: Rapid erosion beneath the Greenland ice sheet, Geology, 40, 343-346, doi:10.1130/G32687.1, 2012.
Cuffey, K. M. and Paterson, W. S. B.: The Physics of Glaciers, 4th Edition, 4th Edn., Elsevier, Burlington, MA, 704 pp., 2010.

Das, S. B., Joughin, I., Behn, M. D., Howat, I. M., King, M. A., Lizarralde, D., and Bhatia, M. P.: Fracture propagation to the base of the Greenland Ice Sheet during supraglacial lake drainage, Science, 320, 778-781, 2008.

Doyle, S. H., Hubbard, A. L., Dow, C. F., Jones, G. A., Fitzpatrick, A., Gusmeroli, A., Kulessa, B., Lindback, K., Pettersson, R., and Box, J. E.: Ice tectonic deformation during the rapid in situ drainage of a supraglacial lake on the Greenland Ice Sheet, The Cryosphere, 7, 129-140, doi:10.5194/tc-7-129-2013, 2013.

Flowers, G. E., Bjornsson, H., Palsson, F., and Clarke, G. K. C.: A coupled sheet-conduit mechanism for jokulhlaup propagation, Geophys. Res. Lett., 31, L05401, doi:10.1029/2003g1019088, 2004.

Hoffman, M. J., Catania, G. A., Neumann, T. A., Andrews, L. C., and Rumrill, J. A.: Links between acceleration, melting, and supraglacial lake drainage of the western Greenland Ice Sheet, J. Geophys. Res.-Earth, 116, F04035, doi:10.1029/2010jf001934, 2011.

Iken, A.: The effect of the subglacial water-pressure on the sliding velocity of a glacier in an idealized numerical-model, J. Glaciol., 27, 407-421, 1981.

Joughin, I.: Ice-sheet velocity mapping: A combined interferometric and speckle-tracking approach, Ann. Glaciol., 34, 195-201, 2002.

Joughin, I., Das, S. B., King, M. A., Smith, B. E., Howat, I. M., and Moon, T.: Seasonal speedup along the western flank of the Greenland Ice Sheet, Science, 320, 781-783, 2008.

King, M. and Aoki, S.: Tidal observations on floating ice using a single GPS receiver, Geophys. Res. Lett., 30, 1138, doi:10.1029/2002GL016182, 2003.

Krawczynski, M. J., Behn, M. D., Das, S. B., and Joughin, I.: Constraints on the lake volume required for hydrofracture through ice sheets, Geophys. Res. Lett., 36, L10501, doi:10.1029/2008gl036765, 2009.

Palmer, S., Shepherd, A., Nienow, P., and Joughin, I.: Seasonal speedup of the Greenland Ice Sheet linked to routing of surface water, Earth Planet. Sc. Lett., 302, 423-428, doi:10.1016/J.Eps1.2010.12.037, 2011.

Parizek, B. R. and Alley, R. B.: Implications of increased Greenland surface melt under global-warming scenarios: ice-sheet simulations, Quaternary Sci. Rev., 23, 1013-1027, 2004.

Phillips, T., Leyk, S., Rajaram, H., Colgan, W., Abdalati, W., McGrath, D., and Steffen, K.: Modeling moulin distribution on Sermeq Avannarleq glacier using ASTER and WorldView imagery and fuzzy set theory, Remote Sens. Environ., 115, 2292-2301, doi:10.1016/J.Rse.2011.04.029, 2011.

Pimentel, S. and Flowers, G. E.: A numerical study of hydrologically driven glacier dynamics and subglacial flooding, P. Roy. Soc. A-Math. Phy., 467, 537-558, doi:10.1098/Rspa.2010.0211, 2011.

Röthlisberger, H.: Water pressure in intra- and subglacial channels, J. Glaciol., 11, 177-203, 1972.

Schoof, C.: Ice-sheet acceleration driven by melt supply variability, Nature, 468, 803-806, doi:10.1038/nature09618, 2010.

Selmes, N., Murray, T., and James, T. D.: Fast draining lakes on the Greenland Ice Sheet, Geophys. Res. Lett., 38, L15501, doi:10.1029/2011GL047872, 2011. 
Sole, A. J., Mair, D. W. F., Nienow, P. W., Bartholomew, I. D., King, M. A., Burke, M. J., and Joughin, I.: Seasonal speedup of a Greenland marine-terminating outlet glacier forced by surface melt-induced changes in subglacial hydrology, J. Geophys. Res.-Earth, 116, F03014, doi:10.1029/2010jf001948, 2011.

Sundal, A. V., Shepherd, A., Nienow, P., Hanna, E., Palmer, S., and Huybrechts, P.: Evolution of supra-glacial lakes across the Greenland Ice Sheet, Remote Sens. Environ., 113, 2164-2171, doi:10.1016/J.Rse.2009.05.018, 2009.

Sundal, A. V., Shepherd, A., Nienow, P., Hanna, E., Palmer, S., and Huybrechts, P.: Melt-induced speed-up of Greenland ice sheet offset by efficient subglacial drainage, Nature, 469, 522-U583, doi:10.1038/Nature09740, 2011.

Tsai, V. C. and Rice, J. R.: A model for turbulent hydraulic fracture and application to crack propagation at glacier beds, J. Geophys. Res.-Earth, 115, F03007, doi:10.1029/2009jf001474, 2010.

van Angelen, J. H., Lenaerts, J. T. M., Lhermitte, S., Fettweis, X., Kuipers Munneke, P., van den Broeke, M. R., van Meijgaard, E., and Smeets, C. J. P. P.: Sensitivity of Greenland Ice Sheet surface mass balance to surface albedo parameterization: a study with a regional climate model, The Cryosphere, 6, 1175-1186, doi:10.5194/tc-6-1175-2012, 2012. van de Wal, R. S. W., Boot, W., van den Broeke, M. R., Smeets, C., Reijmer, C. H., Donker, J. J. A., and Oerlemans, J.: Large and rapid melt-induced velocity changes in the ablation zone of the Greenland Ice Sheet, Science, 321, 111-113, 10.1126/science.1158540, 2008.

van der Veen, C. J.: Fracture propagation as means of rapidly transferring surface meltwater to the base of glaciers, Geophys. Res. Lett., 34, L01501, doi:10.1029/2006GL028385, 2007.

Walder, J. S.: Stability of sheet flow of water beneath temperate glaciers and implications for glacier surging, J. Glaciol., 28, 273293, 1982.

Whillans, I. M. and Johnsen, S. J.: Longitudinal Variations in Glacial Flow - Theory and Test Using Data from the ByrdStation Strain Network, Antarctica, J. Glaciol., 29, 78-97, 1983.

Zwally, H. J., Abdalati, W., Herring, T., Larson, K., Saba, J., and Steffen, K.: Surface melt-induced acceleration of Greenland icesheet flow, Science, 297, 218-222, 2002. 